

\title{
Modeling of Corrosion-Induced Damage in Reinforced Concrete Considering Electro-Mechanical Coupling
}

\author{
Di Qiao $^{1^{*}}$, Hikaru Nakamura $^{2}$, Yoshihito Yamamoto ${ }^{3}$ and Taito Miura ${ }^{4}$
}

\begin{abstract}
This paper presents an electro-mechanical model for evaluating the corrosion-induced damage in reinforced concrete under accelerated conditions. The model consists of structural analysis of concrete and the rebar using the Rigid Body Spring Method and corrosion current analysis with the truss networks model. The electric corrosion process is coupled with concrete cracking conditions by relating current efficiency to local crack width; the predicted radius losses of rebars are used to evaluate concrete crack propagation and residual tensile performance of corroded rebars. The model is validated with the results of accelerated corrosion tests using impressed current and a sodium chloride pond on the concrete cover. Good agreement with the test data is obtained with the proposed model, in terms of corrosion degree and profile, concrete crack pattern, and tensile behavior of corroded rebars. The model offers a corroborative tool with the accelerated corrosion technique to study the mechanical behavior of corroded concrete structures.
\end{abstract}

\section{Introduction}

Chloride-induced corrosion of reinforcing steel bars (rebars) in concrete is a major cause of deterioration of reinforced concrete (RC) structures. Corrosion may result in several forms of damage on reinforced concrete: loss of effective concrete section due to concrete cracking and cover spalling, loss of rebar tensile performance due to a reduced cross-section, and a decrease of bond strength between corroded rebars and concrete. The damage cannot only compromise the load-bearing capacity of an RC structure, but can also pose risk to human safety if concrete falling would occur. To assess the damage of a corroded RC structure, it is of great importance to have a numerical model, which is able to model the influence of corrosion on the mechanical behavior of concrete and the rebar. Such model could provide useful information for maintenance works of RC structures that are exposed to chloride-laden environments.

To evaluate the corrosion-induced damage on concrete and the rebar, local radius losses of the rebar are needed to predict the expansion pressure caused by volume increase of corrosion products (Lundgren 2002), and to estimate the reduction of rebar cross-section area and the residual tensile capacity (Cairns et al. 2005; Qiao et al. 2015a). It is well known that corrosion-

\footnotetext{
${ }^{1}$ Postdoctoral fellow, Department of Civil Engineering, Nagoya University, Nagoya, Japan.

*Corresponding author, E-mail: rudyqiao@gmail.com

${ }^{2}$ Professor, Department of Civil Engineering, Nagoya University, Nagoya, Japan.

${ }^{3}$ Associate Professor, Department of Civil Engineering, Nagoya University, Nagoya, Japan.

${ }^{4}$ Assistant Professor, Department of Civil Engineering, Nagoya University, Nagoya, Japan.
}

caused cracks can help to speed up the penetration of chlorides, oxygen, and water into the concrete, thereby accelerating the corrosion process and causing more cracks (Bažant 1979; Djerbi et al. 2008). Hence the coupling between corrosion and concrete cracking should be considered for predicting the radius losses. Although a few coupled chemo-hygro-thermo mechanical models concerned with rebar corrosion in cracked concrete have been proposed (Ishida et al. 2009; Ožbolt et al. 2012), the modeling of this coupled process is still challenging. The main difficulty exists in model validation due to lack of available test data.

On the other hand, in the experimental study of corrosion-caused damage, the accelerated corrosion technique using impressed current is widely used, since with this method a high corrosion degree can be obtained within a reasonably short time frame (Poursaee and Hansson 2009). Prior to the mechanical testing of corroded RC specimens, the general corrosion degree and the distribution of localized corrosion often need to be considered in order to perform a safe and meaningful test (Coronelli and Gambarova 2004). In particular, when testing the specimens subjected to a high corrosion degree, it accompanies a risk of brittle failure. It is, however, not easy to obtain the relevant information of corrosion without extracting the embedded rebars. According to Malumbela et al. (2012), both surface crack width and mass loss predicted by Faraday's law may be inappropriate parameters to indicate corrosion degree. Therefore, a numerical model capable of predicting the electric corrosion process and its resulting damage on concrete and the rebar could be useful. With this model, the numerical analysis can be instrumental in structural testing.

This study focuses on modeling of the damage caused by accelerated corrosion, including concrete crack propagation and degradation of tensile performance of 
the rebar. An electro-mechanical model is developed using the Rigid Body Spring Method (RBSM) for structural analysis of concrete and the rebar, combined with the truss networks model for corrosion current analysis. The electro-mechanical coupling is described by relating current efficiency to local crack width. The model is validated with the results of an electric corrosion test. Moreover, the proposed model is applied to analyze the crack pattern caused by localized corrosion along the rebar length.

\section{Experimental study}

The purpose of this experiment study is to provide essential data for validation of the electro-mechanical model. In the corrosion test, the impressed current method using a sodium chloride $(\mathrm{NaCl})$ pond built on the concrete cover was employed to accelerate the corrosion process. Considering various corrosion degrees, corrosion profiles represented by radius losses along the rebar, concrete cracking situations and tensile performance of the corroded rebars were examined.

\subsection{Geometry and material properties}

The specimens investigated in this study were prismatic concrete of $200 \times 500 \times 200 \mathrm{~mm}^{3}$, with a cast-in round rebar of $16 \mathrm{~mm}$ in diameter and concrete cover of $30 \mathrm{~mm}$, as shown in Fig. 1. The $600 \mathrm{~mm}$ long rebar was embedded along the $200 \mathrm{~mm}$ length of each specimen, with exposed parts extending $200 \mathrm{~mm}$ beyond each end. After the corrosion test, the radius losses of corroded rebars were measured using a laser meter. Due to a limitation of the laser meter in scanning length, the length of the corroded part was confined to $180 \mathrm{~mm}$ by coating the other parts with anti-corrosion paint, waterproof tape and insulating tape in sequence to prevent from corroding. These rebars with anti-corrosion covers were measured for original weights before casting the concrete.

The concrete was made using High Early Strength
Table 1 Mixture proportion of concrete.

\begin{tabular}{|c|c|c|c|c|c|c|}
\hline W/C & s/a & \multicolumn{5}{|c|}{ Unit $\left(\mathrm{kg} / \mathrm{m}^{3}\right)$} \\
\cline { 5 - 7 }$(\%)$ & $(\%)$ & Water & Cement & Sand & Aggregate & AE (liter/m $\left.{ }^{3}\right)$ \\
\hline 56.5 & 44 & 166 & 294 & 779 & 990 & 1.18 \\
\hline
\end{tabular}

Table 2 Test variables.

\begin{tabular}{|c|c|c|}
\hline Series & $\begin{array}{c}\text { Testing time } \\
\text { (hours) }\end{array}$ & $\begin{array}{c}\text { Current flow } \\
(\mathrm{A} \text { *hr })\end{array}$ \\
\hline T86, T205, & $86.18,204.53$, & $6.89,16.36$, \\
T341, T500, & $340.89,500.0$, & $27.27,40.0$, \\
T625 & 625.0 & 50.0 \\
\hline
\end{tabular}

Cement for reducing the curing time. Table 1 shows the mixture proportion of concrete. Coarse aggregates were used with a maximum size of $20 \mathrm{~mm}$. After casting, the specimens were cured in a room at $20^{\circ} \mathrm{C}$ for 14 days. Prior to the corrosion test, the Young's modulus, compressive strength and splitting tensile strength of the concrete were determined as $30.75 \mathrm{GPa}, 38.45 \mathrm{MPa}$ and $2.94 \mathrm{MPa}$, respectively. The rebar was plain steel reinforcement bar SR235 (JIS 2010) with yield strength greater than $235 \mathrm{MPa}$ and ultimate tensile strength greater than $380 \mathrm{MPa}$. The plain round rebars were used for easily measuring radius losses with a laser meter.

\subsection{Accelerated corrosion test setup}

In order to accelerate the corrosion process, the electrochemical method using impressed current was used as shown in Fig. 2. A constant direct current was applied between the rebar (anode) and a copper plate (cathode) inside a pond filled with $3 \% \mathrm{NaCl}$ solution, located on the concrete cover. No chlorides were added to the concrete mix. Hence only the top surface of the concrete specimens would be contaminated with chlorides. Under such conditions, steel corrosion could be localized within the direction of chloride ingress (Malumbela et al. 2009; Qiao et al. 2015b), which can reasonably represent natural steel corrosion caused by external chlorides.

The corrosion time was varied as shown in Table 2 to
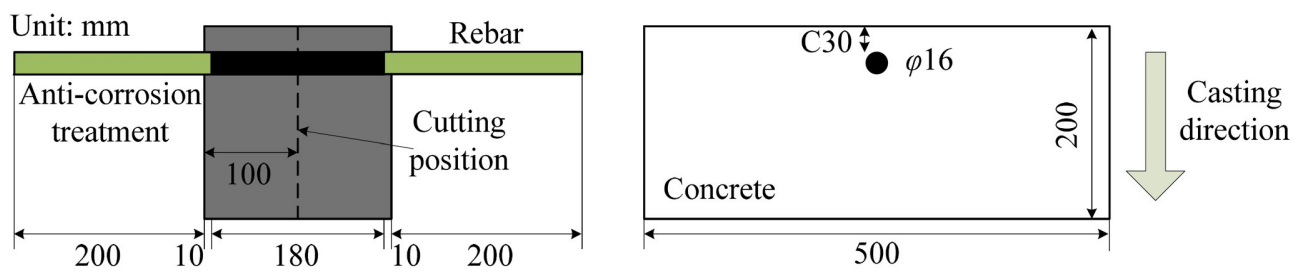

Fig. 1 Geometry of test specimens.

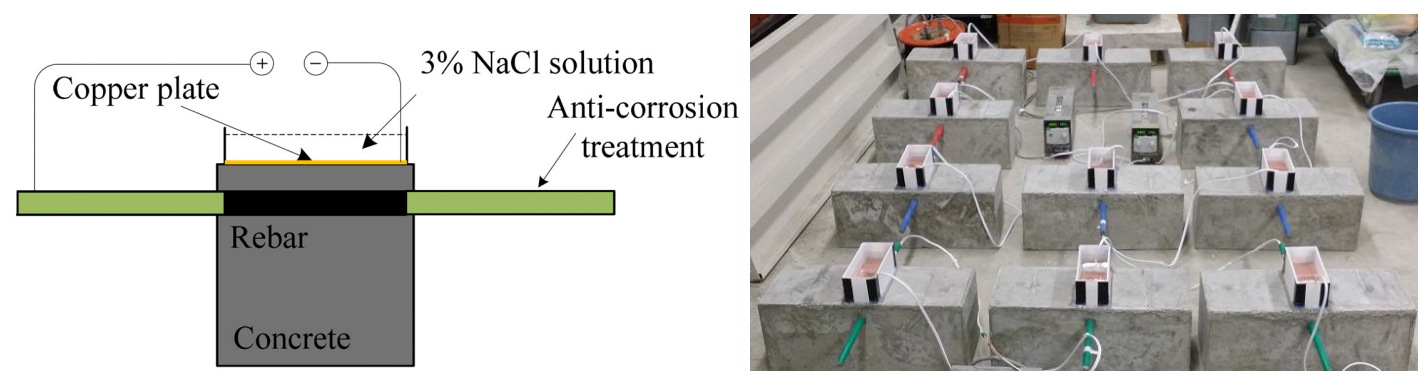

Fig. 2 Details of accelerated corrosion tests. 
obtain different corrosion degrees. The specimen names were assigned in the form T86, meaning a period of approximately 86hours applied with the direct current. Four specimens were used for each test series, of which three were for investigating corrosion profile and rebar tensile performance, and the other one for concrete crack pattern. They were connected in series to a DC power and supplied with the current of $0.08 \mathrm{~A}$, as shown in Fig. 2. The nominal current density applied was about $900 \mu \mathrm{A} / \mathrm{cm}^{2}$ to allow quick crack generation, as referred to in other reported electric corrosion tests (Mangat and Elgarf 1999; Yuan et al. 2007).

\subsection{Corrosion degree}

After the corrosion test, the specimens designed for measuring corrosion profile were broken, and the rebars embedded were extracted. These rebars were cleaned using a steel wire brush, and the corrosion products were removed by immersing the rebars in a $10 \%$ ammonium citrate solution for 24 hours. The mass loss $\Delta m$ (g) of each rebar measured as the difference between the original and remaining weights was used to determine the corrosion degree $\eta$ over the whole corroded area with a length of $l_{\mathrm{c}}$ :

$$
\eta=\Delta m /\left(l_{c} m_{u}\right)
$$

where $m_{\mathrm{u}}$ is the unit mass $(1.58 \mathrm{~g} / \mathrm{mm})$ and $l_{\mathrm{c}}$ is the corroded length $(180 \mathrm{~mm})$. To compare the real gravimetrical mass loss and the theoretical value given by Faraday's law, the current efficiency $N$ was obtained as the ratio between the two values:

$$
N=\Delta m /\left(\frac{I t M}{n F}\right)
$$

where $I$ is the current intensity $(0.08 \mathrm{~A}), t$ is the corrosion time (s), $M$ is the molar mass of iron $(55.85 \mathrm{~g} / \mathrm{mol})$, $n$ is the valency $(n=2)$, and $F$ is Faraday's constant $\left(9.65 \times 10^{4} \mathrm{C} / \mathrm{mol}\right)$.

Figure 3 shows the development of corrosion degree against current flow, in which the corresponding current efficiency for each case is indicated. It appears that the real corrosion degrees measured are much smaller than those estimated based on Faraday's law. This low current efficiency suggests that oxidation of steel is not the main anodic process involved in the present corrosion test. Several researchers (Caré and Raharinaivo 2007;
Nossoni and Harichandran 2012; Duffó et al. 2015) have also observed low efficiencies in the corrosion tests with low contents of chloride in the concrete, as is the case of the present work. Nossoni and Harichandran (2012) postulated that for low chloride contents there are competitive reactions in the anode. During our test, it was observed that some gases bubbled out of the $\mathrm{NaCl}$ pond. Although these gases were not identified chemically, they were assumed to be oxygen and hydrogen, the products of water splitting that might have consumed a part of the applied current. As the corrosion time increased, it was found that the current efficiency slightly increased, implying an increase of corrosion rate.

\subsection{Corrosion profile}

The corrosion profiles of the corroded rebars were then measured using the laser meter with a precision of $0.1 \mu \mathrm{m}$. For each rebar sample, various measurement lines around the rebar were tested, which were located at different circumferential positions with an interval of $30^{\circ}$, as shown in Fig. 4. The top line is the nearest side to the concrete surface contaminated with chlorides. The measurement interval along each test line was $50 \mu \mathrm{m}$.

During the test, non-corroded parts at the sides of the corroded area were used as reference levels, with which the measured values were transformed into relative heights. For each rebar sample, the height level before the corrosion test was obtained as the initial level. The radius loss was thus determined as the difference be-

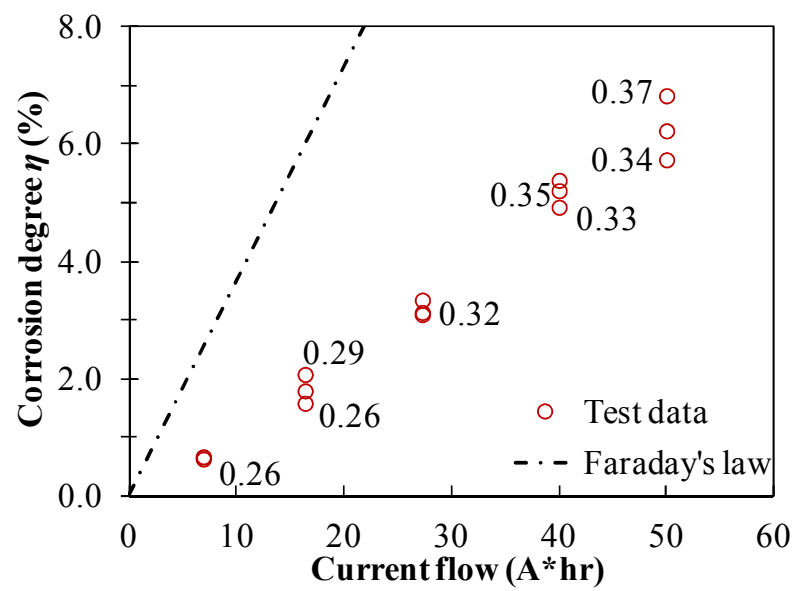

Fig. 3 Measured corrosion degree.

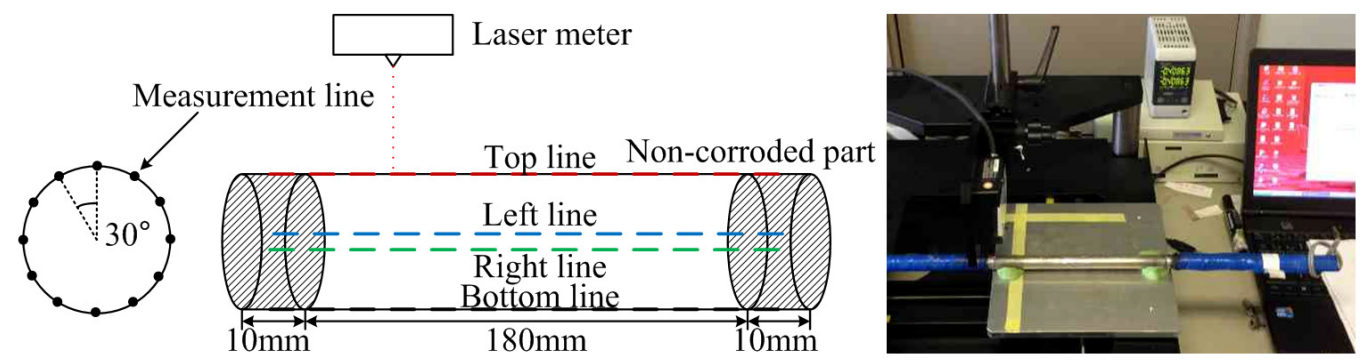

Fig. 4 Measuring corrosion profiles by laser meter. 
tween the initial level and the measurement level after the corrosion test. A Fast Fourier Transform was conducted to eliminate the measurement noise caused by imperceptible vibrations of the rebar samples, and then an Inverse Fourier Transform was conducted to obtain a smooth distribution of radius losses. Microwaves with frequencies of more than five wave periods in each $10 \mathrm{~mm}$ of length were eliminated in this process (Mada 2011).

In order to clarify the corrosion pattern, the radius losses measured along the top and bottom lines are compared in Fig. 5. It seems that the corrosion distributed continuously along the rebar length. With an increase of corrosion time, the radius losses along the top line clearly increased, whereas those along the bottom line hardly changed. Figure 6 shows the remaining cross sections of the rebar samples described with the average radius loss along each measurement line. The corrosion at the upper circumference was observed to be more severe than that at the lower part, showing a typical non-uniform corrosion pattern.

\subsection{Concrete crack pattern}

To investigate internal crack pattern, the specimens without extraction of rebars (one specimen for each test series) were cut along the center section as plotted in Fig. 1. Figure 7 shows a comparison of the internal crack patterns under different corrosion degrees. In the case of T86 with a comparatively low corrosion degree of $0.65 \%$, no visible cracks could be found, and the rebar was nearly corroded uniformly (Fig. 6). It was then observed that a visible vertical crack initiated from the

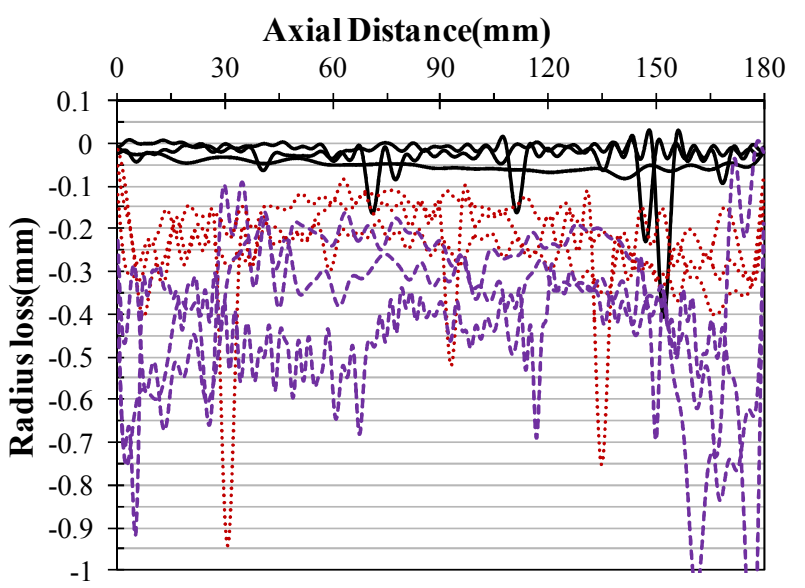

(a) Top line

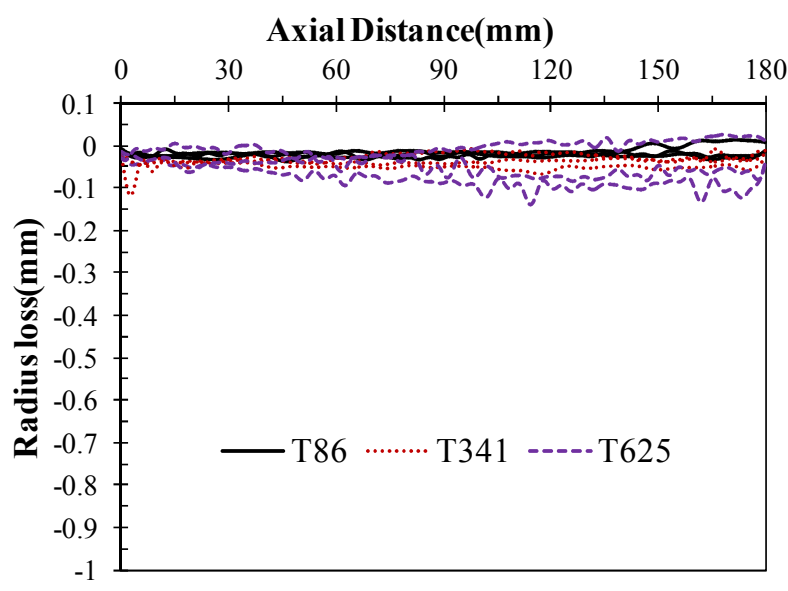

(b) Bottom line

Fig. 5 Measured radius losses along the rebar.

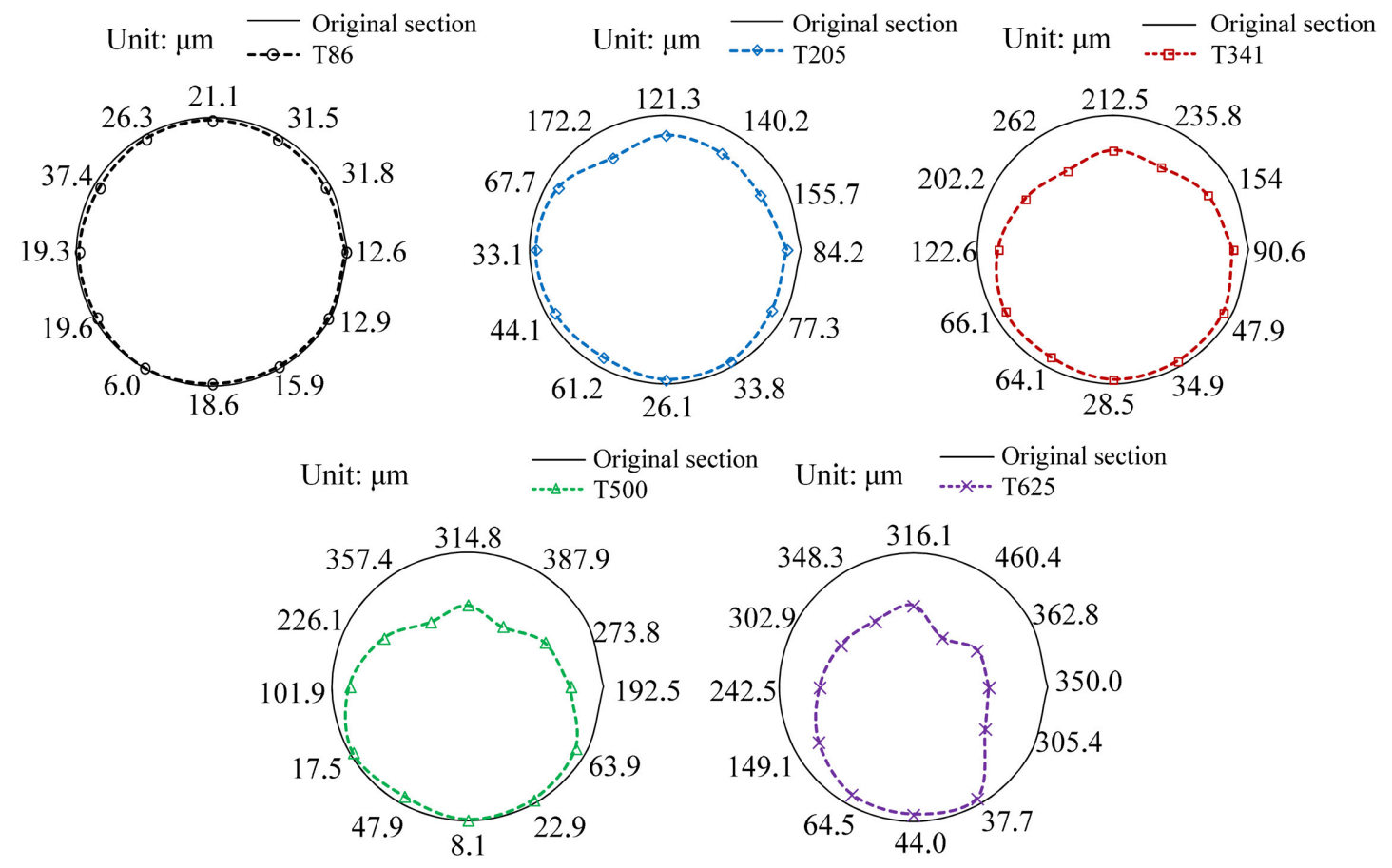

Fig. 6 Residual cross-sections of rebars after corrosion test. 

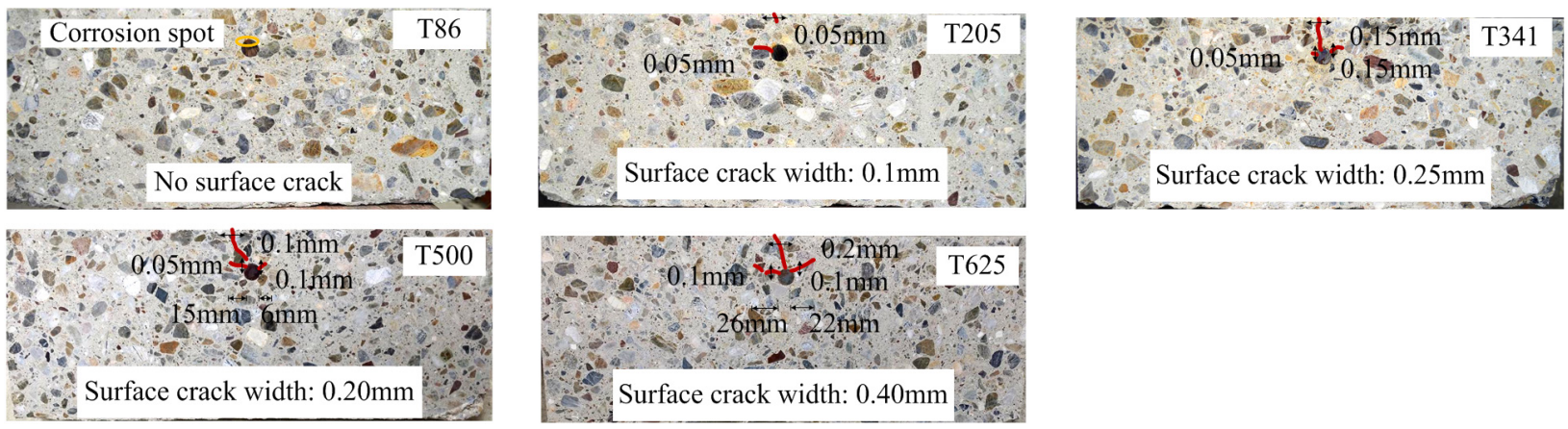

Fig. 7 Internal crack patterns at various corrosion amounts.

concrete surface. As the corrosion time increased, the crack opening on the concrete surface became larger, and the vertical crack propagated to the rebar with appearance of lateral cracks. The forming vertical crack can provide a flow channel for chlorides and thereby increase the corrosion rate of the rebar upper part, as shown in Fig. 6.

\subsection{Tensile performance of corroded rebars}

After measuring the corrosion degrees and profiles, the rebar samples were tested for examining the tensile performance. Uniaxial tension tests of non-corroded and corroded rebar samples were carried out with a universal testing machine. The tension testing length from the upper chucked point of a rebar sample to the lower one was $400 \mathrm{~mm}$, containing the $180 \mathrm{~mm}$ long corroded zone. The tensile load was applied with a speed of $250 \mathrm{~N} / \mathrm{s}$ and recorded using a data collecting and processing system. To obtain the development of local strains along the rebar length, five strain gauges were attached to the corroded zone with a spacing of $40 \mathrm{~mm}$. Additionally, a digital image processing method using distinguishable round spots on the rebar surface was employed to obtain the strains up to tensile failure as they often exceed the upper measurement limit of the strain gauge. Detailed descriptions of the test procedures and the digital image processing method can be found in (Qiao et al. 2015a).

Figure 8 shows the load-elongation curves of the

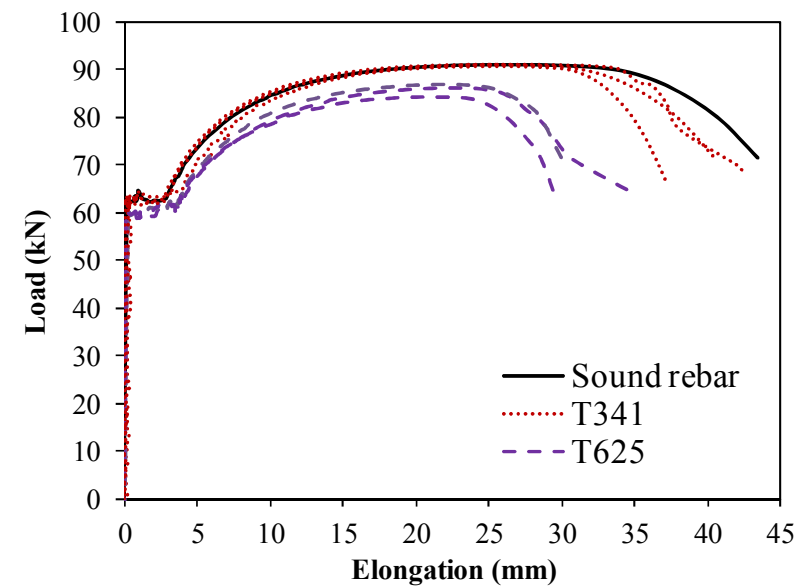

Fig. 8 Load-elongation curves of corroded rebar specimens.
T341 and T625 cases with corrosion degrees ranging from $3.1 \%$ to $6.83 \%$, which are compared with that of the non-corroded rebar sample. Elongation was calculated based on deformation of the fracture zone, which has an original length of $128 \mathrm{~mm}$ i.e. eight times the diameter of the non-corroded rebar (JIS 2011). It was observed that the tensile performance of the corroded rebar samples decreases clearly as the corrosion degree increases. Up to $6.26 \%$ corrosion (averaged corrosion degree for T625 cases), the yield and ultimate loads dropped a little, $3.4 \%$ for yield load and $6.4 \%$ for ultimate load, while the elongation decreased significantly $(18.1 \%)$. This test result is similar to those found by Morinaga (1996) and Zhang et al. (2012).

\section{Electro-mechanical model}

The evaluation of the damage caused by accelerated corrosion requires proper modeling of the electric corrosion process of rebars. The test results demonstrated that forming concrete cracks affect the corrosion rate and corrosion distribution. In the newly developed electromechanical model, the corrosion process is coupled with the cracking conditions of concrete.

\subsection{Three-dimensional RBSM}

The electro-mechanical model is based on threedimensional RBSM developed by Yamamoto et al. (2008, 2014). The RBSM is a discrete numerical approach, which represents a continuum material as an assemblage of rigid particle elements interconnected by zero-length springs along their boundaries, as shown in Fig. 9. The elements are randomly generated with Voronoi Diagram (Bolander and Saito 1998). Each element

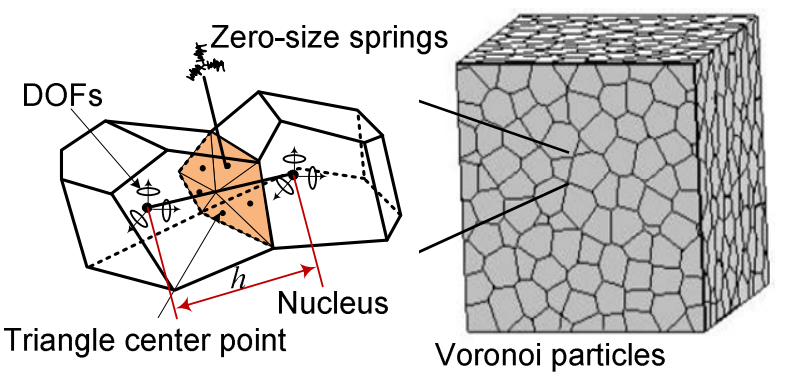

Fig. 9 Voronoi particle definition of RBSM element. 
has six degrees of freedom at its nucleus. The boundary between two elements is divided into triangles formed by the center of gravity and the vertices. At the center point of each triangle, three springs, one normal and two shear springs are defined. The response of the spring networks provides an understanding of the interaction between particle elements instead of the internal behavior of each element based on continuum mechanics. In a RBSM model, cracks appear at the boundaries between adjacent particle elements. The crack widths can be automatically calculated as relative displacements between the centers of particles. It is possible to quantitatively study the effects of cracking on the transport properties of concrete using three-dimensional RBSM model.

\subsection{Material models of concrete}

Figure 10 shows the material models of concrete used in the analysis. The tensile and compressive models are introduced into the normal springs, where $f_{\mathrm{t}}$ represents tensile strength, $h$ is the distance between centers of the elements, $G_{\mathrm{F}}$ is tensile fracture energy. $f_{\mathrm{c}}$ ' is compressive strength, $G_{\mathrm{Fc}}$ is compressive fracture energy, and $E$ is Young's modulus. The shear model is introduced into the shear springs, in which the shear strength is assumed to follow the Mohr-Coulomb type criterion with the tension and compression caps. For cracked interfaces, a softening branch is assumed after the shear stress reaches the shear strength, as shown in Fig. 10 (b). In addition, given that the shear transferring capacity at the cracked interface changes according to the crack opening, the shear stiffness $G$ is reduced by using a function of the strain normal to the crack as shown in the shearreduction model. The material parameters of concrete were determined by tension and compression simulations of a standard cylinder, which were compared with test data.

\subsection{Truss networks model}

Field-type problems and mass transfer situations, which are governed by partial differential equations, are usually analyzed using a continuum model. The RBSM as a discrete approach, however, does not require continuity. In this study, the truss networks model (Nakamura et al. 2006) was incorporated to analyze the electric corrosion process for deriving radius losses along the rebar.

To construct the truss networks, the particle elements in a RBSM model are linked by truss elements with a node at the nucleus of each particle and at the intermediate points on each boundary, as shown in Fig. 11. A simplified one-dimensional partial differential equation is applied to the truss networks to simulate mass transfer within bulk concrete. This method was used herein to calculate the electric potential in concrete.

It is well known that mass transfer through cracked concrete is faster than that through sound concrete. The presented experimental work showed that the electric corrosion process is greatly influenced by cracks as well.

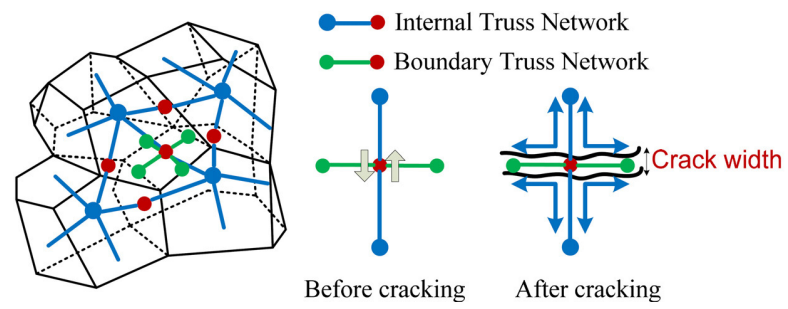

Fig. 11 Truss networks model.

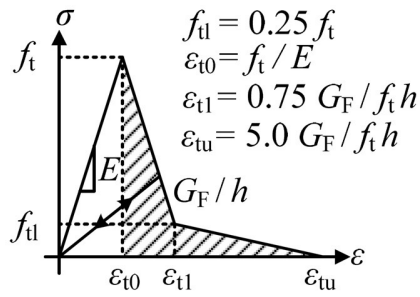

Tensile response

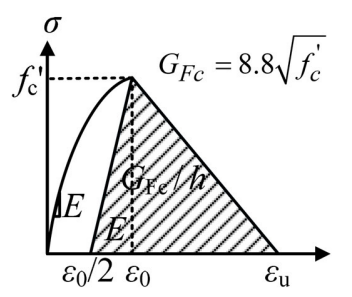

Compressive response

(a) For normal springs
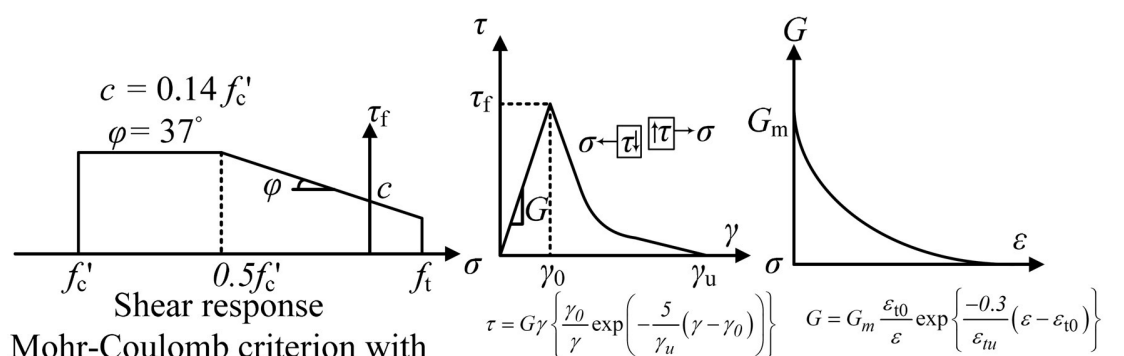

Mohr-Coulomb criterion with tension and compression caps

Shear softening model

Shear reduction model

(b) For shear springs

Fig. 10 Concrete material model. 
To consider this influence, the truss elements are also set on the boundaries between particle elements, and the cross-section area of such truss element depends on crack width. That is, before cracking, the cross-section area is zero, and mass transfer is not allowed through the truss element on the boundary; after cracking, the cross-section area is determined by multiplying the crack width with the length of sides of the boundary, and mass transfer can happen both within bulk concrete and through cracks. In this study, the boundary truss networks in the cracked area were activated to model the effect of forming cracks on the distribution of electric potential. On the other hand, a relationship between

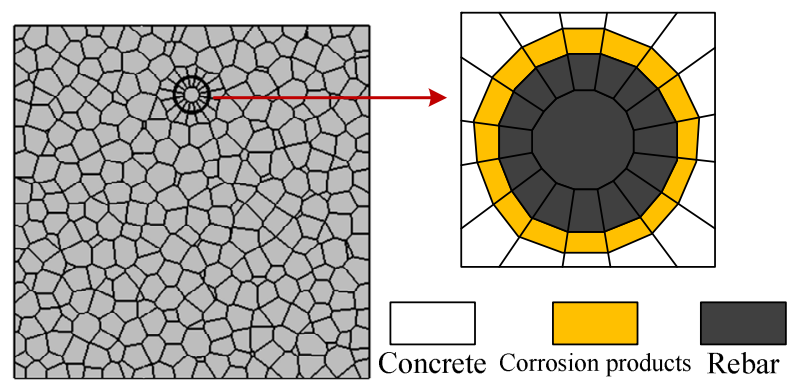

Fig. 12 Three-phase material model.
Table 3 Parameters of relative permittivity (Conyers 2013).

\begin{tabular}{|c|c|c|c|}
\hline Concrete & Rebar & Corrosion products & Salty water \\
\hline 6 & $1^{50}$ & 264 & 88 \\
\hline
\end{tabular}

current efficiency and crack width was assumed, which will be described in the following section.

\subsection{Electro-mechanical coupling}

In order to evaluate corrosion-caused damage, a threephase material model including rebar, concrete and corrosion products was created, as shown in Fig. 12. The concrete elements were random Voronoi elements, while the rebar and corrosion products consisting of regular hexahedral elements.

Figure 13 shows the analytical flow of the electromechanical model, which combines corrosion current analysis by truss networks model, corrosion expansion analysis and tension simulation of rebars by the RBSM.

In the corrosion current analysis, the distribution of potential $\phi$ under an externally applied electric field was calculated using Laplace equation (Moliton 2007). The parameters of relative permittivity $\varepsilon_{r}$ for different materials are shown in Table 3, according to Conyers

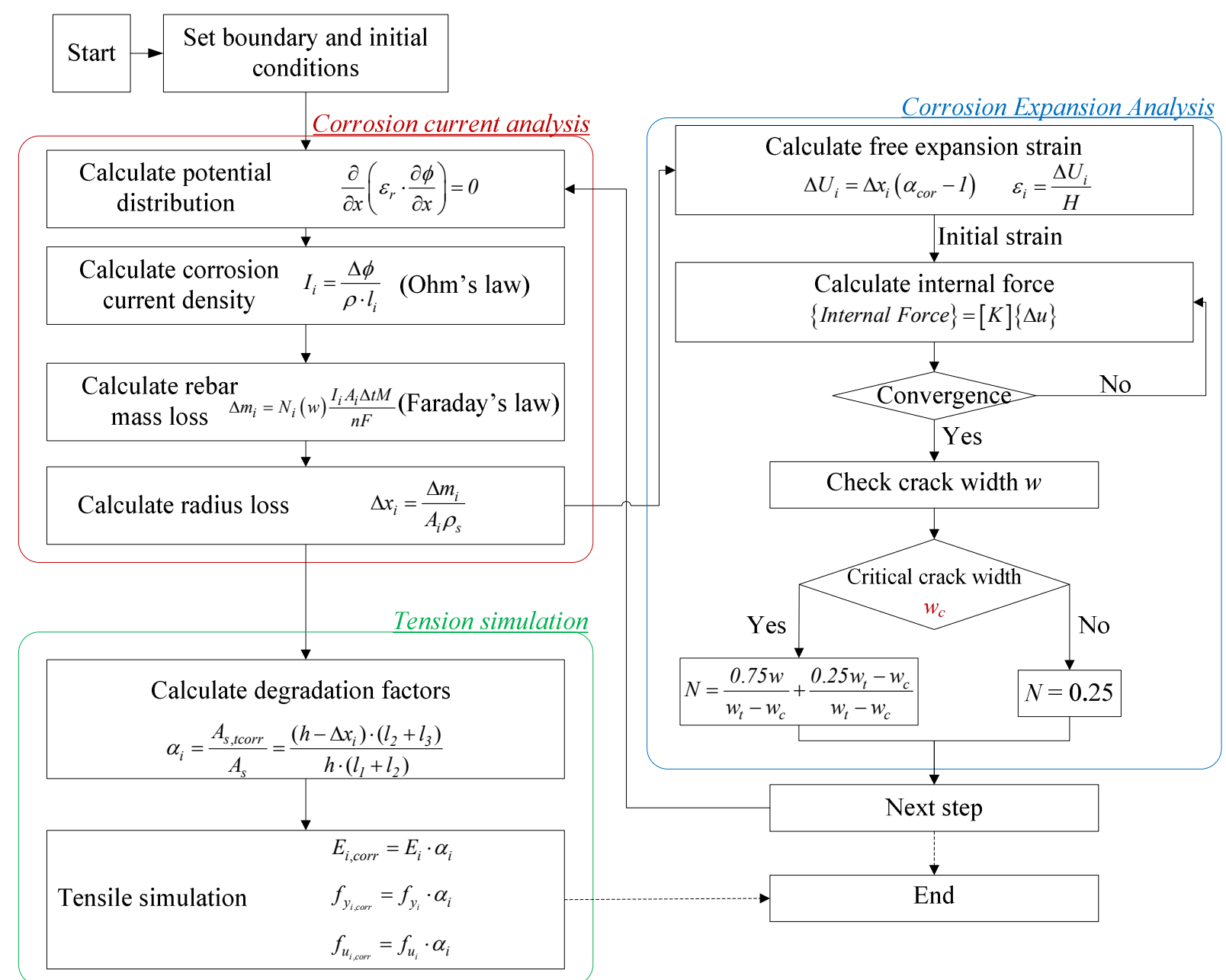

Fig. 13 Coupled electro-mechanical model. 
(2013). Since the corrosion was observed to distribute continuously along the rebars in the corrosion test, it is assumed that only micro-cell corrosion unit was involved. Accordingly, the corrosion current density $I_{i}$ for each corroding rebar element $i$ was obtained with Ohm's law. Then the increment of mass loss $\Delta m_{i}$ was determined with Faraday's law, into which current efficiency $N_{i}$ relating to local crack width $w$ was introduced.

When concrete is exposed to an electric field with the potential drop greater than $10 \mathrm{~V}$, the transport of chlorides in the concrete is mainly due to ions migration and the transport speed is related to diffusion coefficient (Andrade 1993). Djerbi et al. (2008) carried out a steady-state migration test to study the effect of cracks on chloride diffusion into concrete. Their test results demonstrated that the diffusion coefficient through a crack increases with the increasing crack width and becomes almost constant when the crack width is greater than $80 \mu \mathrm{m}$. Hence a growing crack in concrete can result in faster accumulation of chlorides in the area near the crack. This may consequently increase the current efficiency of the rebar part nearby, since the current efficiency depends upon chloride content in the concrete (Nossoni and Harichandran 2012). Accordingly, in the model we assumed that the current efficiency of a corroding rebar element increases if a crack with sufficient opening appears at the neighboring concrete elements. Figure 14 shows the assumed relationship between current efficiency and crack width. Initially the current efficiency $N$ was set as 0.25 , which is in agreement the values found in other reported accelerated corrosion tests with a low content of chlorides in the concrete, 0.23 by Tran et al. (2011) and 0.30 by Nossoni and Harichandran (2012). When a small crack with a width $w_{c}$ was observed near the rebar, the local current efficiency was linearly increased to one until a larger crack width $w_{\mathrm{t}}$. It should be noted that the possible increase of current efficiency due to ingress of chlorides through uncracked concrete was neglected in this model.

In the corrosion expansion analysis, the volume expansion of corrosion products was modeled by internal expansion pressure, which was applied on the boundary

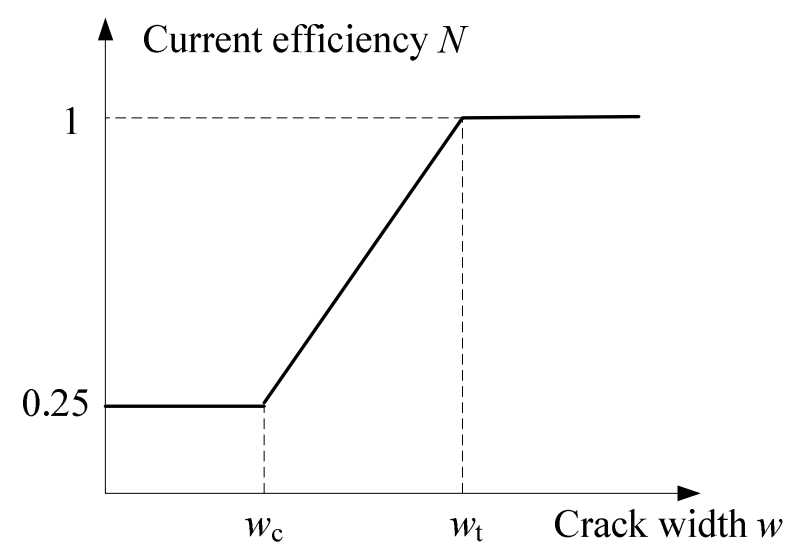

Fig. 14 Assumed relationship between current efficiency and crack width. between the corrosion products layer and the rebar. The rebar was modeled as linear elastic with a Young's modulus of 200GPa. The corrosion products layer assumed with a constant thickness $H$ was also elastic. The former work by Tran et al. (2011) showed that, when $H$ is assumed as $1.0 \mathrm{~mm}$ and the Young's modulus of corrosion products as $500 \mathrm{MPa}$, this model simulates reasonable cracking behavior in comparison with the test results. These assumptions have been adopted herein.

The cracking due to internal expansion pressure was analyzed based on an initial strain problem with increments of free increase of rebar radius $\Delta U_{i}$. The $\Delta U_{i}$ was calculated using the increment of radius loss $\Delta x_{i}$, and the ratio of volume expansion $\alpha_{\text {cor }}$ was assumed as 2.5. Considering the nature of corrosion expansion, we assumed that the expansion pressure is only activated in the normal direction. Hence the initial strains were applied only to the normal springs. On the other hand, the shear stiffness for the shear springs of corrosion products layer was set nearly zero to model free sliding of corrosion products in the shear direction. In each analysis step, the initial strains applied were automatically calculated using the radius losses obtained from the corrosion current analysis. The cracking condition predicted was then used to update local current efficiency and to calculate initial strains for the next step. These procedures form the electro-mechanical coupling.

\subsection{Tension simulation of corroded rebars}

For the tension simulation, an independent rebar model consisting of regular hexahedral elements was created. The stress-strain relationship as described in Fig. 15 was introduced into the normal springs to model the tensile behavior, where $\sigma$ represents tensile stress, $E_{\mathrm{s}}$ is Young's modulus of steel bars, $\varepsilon$ is strain, $\varepsilon_{\mathrm{y}}$ is the strain at the yield stage, $\varepsilon_{\mathrm{sh}}$ is the strain at the hardening stage, $f_{\mathrm{y}}$ is yield strength, $f_{\mathrm{u}}$ is ultimate strength, and $k$ is a constant dependent on the yield strength. The shear behavior was neglected. In this study, the parameters of Young's modulus, yield and ultimate strengths were set as $218.0 \mathrm{GPa}, 318.47 \mathrm{MPa}$, and $463.52 \mathrm{MPa}$, respectively.

In order to model the effect of corrosion on the tensile behavior of rebars, the radius losses along the rebar were extracted from the corrosion current analysis, considering the corrosion degree or corrosion time targeted. The degradation factors $\alpha_{i}$ were then derived from these radius losses, according to which the material properties

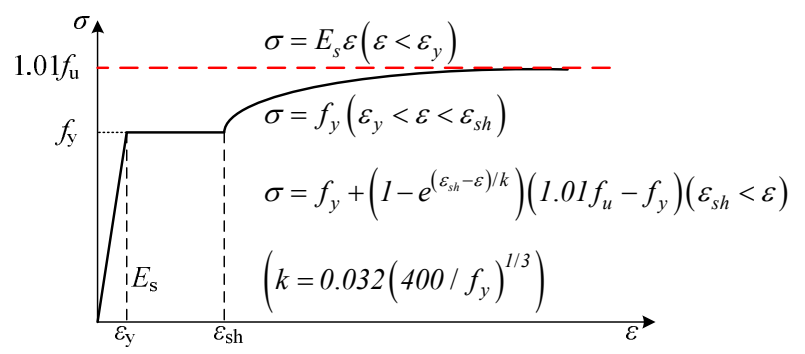

Fig. 15 Stress-strain relationship of rebars subjected to tensile loads (Kato 1979). 
of the corroding rebar elements were reduced as described in Fig. 13 (Qiao et al. 2015a). Figure 16 shows an illustration of the calculation method of degradation factors. In each step of the tension simulation, a constant vertical displacement was applied to the top face of the rebar model, while the bottom face was fixed.

\section{Model validation}

A RBSM model with the same dimension as that of the tested specimens was created as shown in Fig.17 (a), although the extended parts of the rebars were not included in the model. The mesh sizes of the Voronoi particles are $5 \mathrm{~mm}$ in the cover area and $20 \mathrm{~mm}$ in the other area. A structured rebar model with a length of $400 \mathrm{~mm}$ was also created with an element size of $5 \mathrm{~mm}$, as shown in Fig.17 (b).

In the corrosion current analysis, the potential of a rebar element as the anode was simply assumed as $10 \mathrm{~V}$,

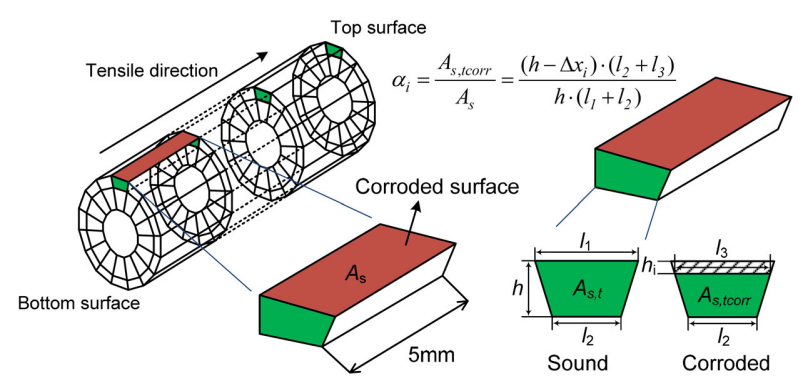

Fig. 16 Calculation of degradation factors for tension simulation.

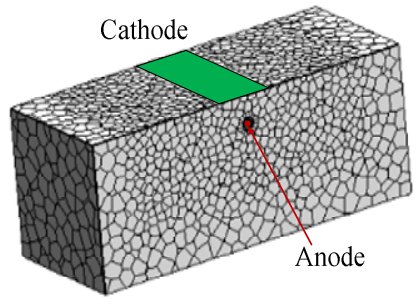

(a) For test specimen

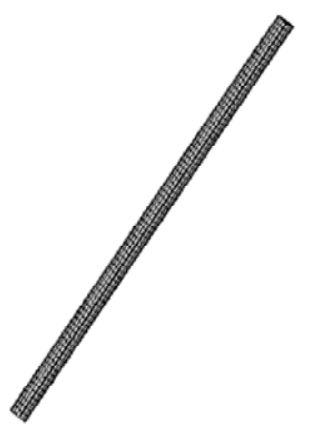

(b) Individual rebar model
Fig. 17 RBSM models of test specimens. while the boundary denoting the cathode was set as zero (Fig. 17). The potential drop between the anode and cathode has the same order of magnitude as that observed in the test. The other boundaries were applied with zero influx condition. The analysis was controlled by ensuring that the calculated current flows are consistent with the test conditions listed in Table 2.

To validate the proposed electro-mechanical model and investigate the effect of cracks on the electric corrosion process, three cases were tested: without considering crack effect, with electro-mechanical coupling and a combination of electro-mechanical coupling and truss networks along cracks.

\subsection{Electric corrosion process \\ 4.1.1 Without crack effect (case I)}

In this case, the corrosion current analysis and the corrosion expansion analysis are independent with each other. The corrosion rates of different parts around the rebar depend upon the potential drop resulting from the electric field applied. Figure 18 shows the simulated potential distribution at the center section of the specimen. It was observed that the potential drop at the upper circumference of the rebar is about two times that at the lower part. This can be attributed to the varying distance from a point on the rebar surface to the cathode. As a result, the corrosion of the rebar upper part can be more serious.

Figure 19 shows the predicted residual cross sections of rebars. The current efficiency was kept as 0.25 in this case. Although the corrosion was observed to concen-

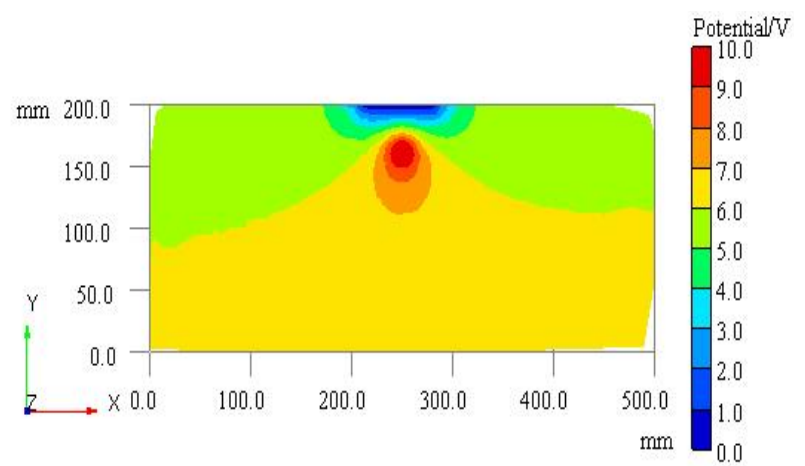

Fig. 18 Calculated potential distribution.

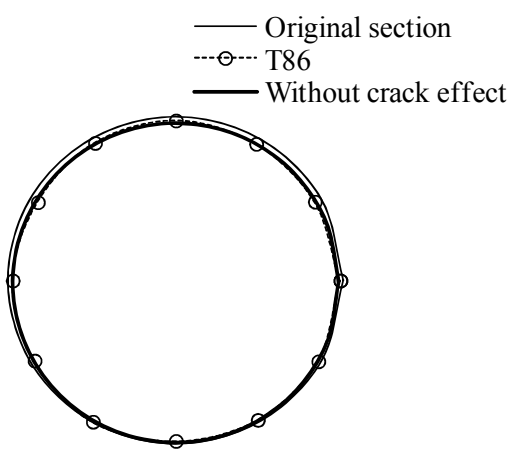

(a) T86

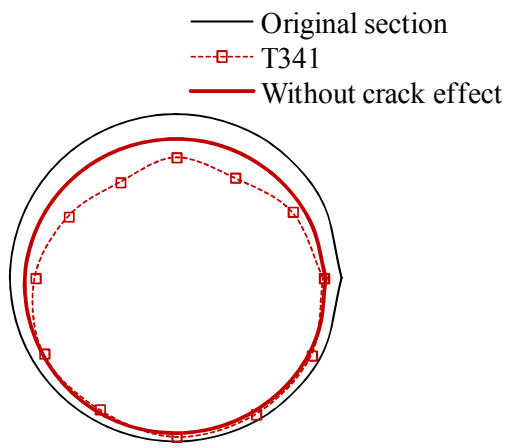

(b) T341

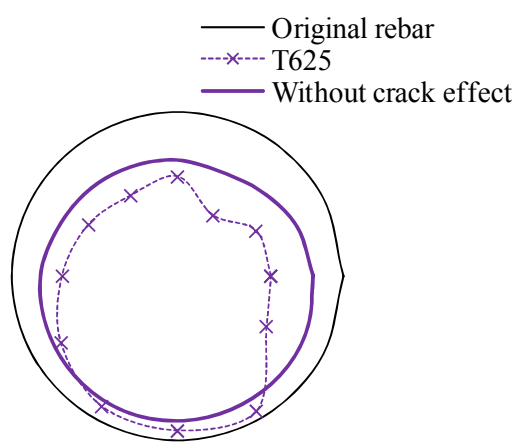

(c) $\mathrm{T} 625$

Fig. 19 Modeled residual cross-sections of rebars without crack effect. 
trate on the upper circumference, the values of radius losses for this part were clearly smaller than those measured in the test, especially for the case with large cracks (T625). Comparing the average radius loss of the top quarter side $\mathrm{RL}_{\mathrm{U}}$ to that of the bottom side $\mathrm{RL}_{\mathrm{D}}$ as shown in Fig. 20, this analysis yielded a constant ratio of 2.47 , whereas in the test the ratio was found to increase gradually with the increase of current flow. The differences suggest that cracks may have a great influence on the circumferential corrosion pattern.

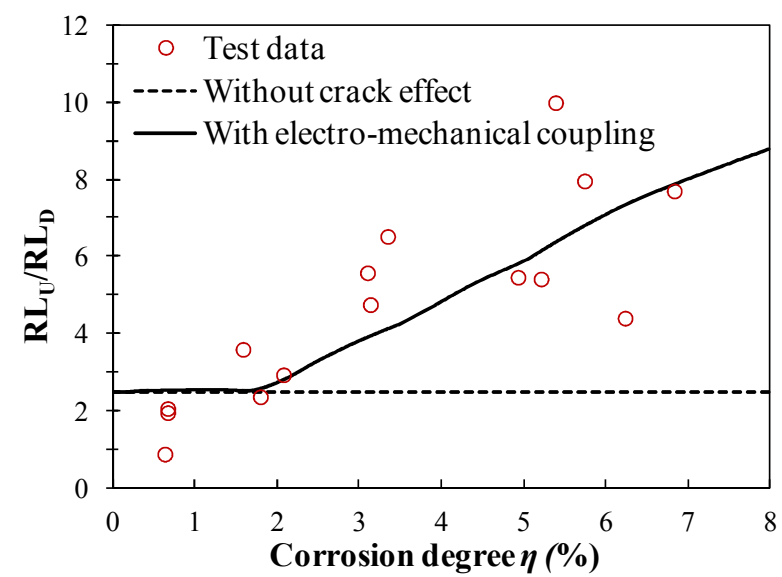

Fig. 20 Ratio of radius losses between top and bottom sides.

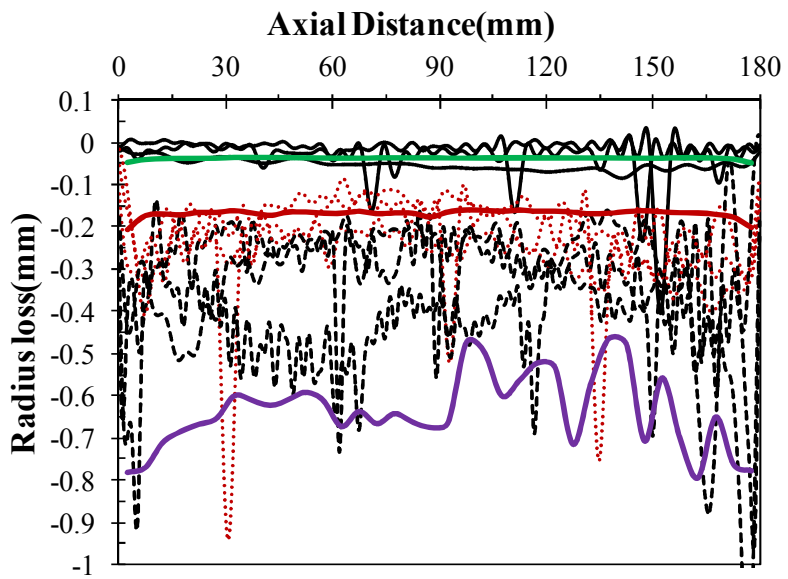

(a) Top line

\subsubsection{With electro-mechanical coupling (case II)}

In the second case, varying values of current efficiency relating to local crack width were considered. Due to lack of test data, it was not easy to derive their relationship from the experiment, specifically the values of $w_{\mathrm{c}}$ and $w_{\mathrm{t}}$ as described in Fig. 14. Therefore, various values were analyzed and the analytical results were compared to the test data. It was found that, when $w_{\mathrm{c}}$ and $w_{\mathrm{t}}$ are assumed as $0.01 \mathrm{~mm}$ and $0.1 \mathrm{~mm}$ respectively, the simulation results best fit the test data in terms of corrosion profile and corrosion process.

Figures 21 and 22 present the radius losses predicted along the axial and circumferential directions of the rebar, showing good agreement with the test results. Moreover, the model with electro-mechanical coupling can capture the increasing difference of corrosion rate between the top and bottom sides of the rebar, as shown in Fig. 20. The development of corrosion degree against current flow obtained in the analysis is shown in Fig. 23. The analytical results agree with the test data. The corrosion rate was observed to increase after the current flow reaching $20.5 \mathrm{~A} * \mathrm{hr}$ when a crack of $0.05 \mathrm{~mm}$ was found on the concrete surface.

\subsubsection{Combination of electro-mechanical cou- pling and boundary truss elements (Case III)}

In the third case, besides the electro-mechanical cou-

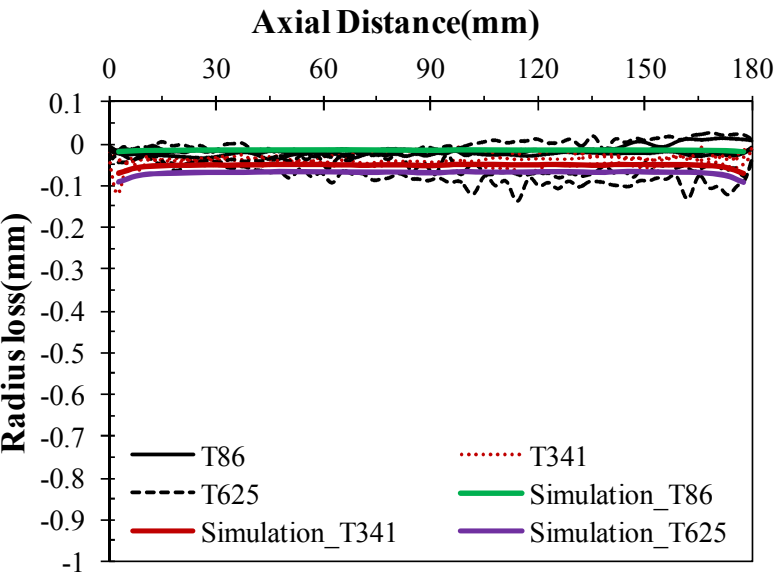

(b) Bottom line

Fig. 21 Modeled radius losses along rebar considering electro-mechanical coupling.

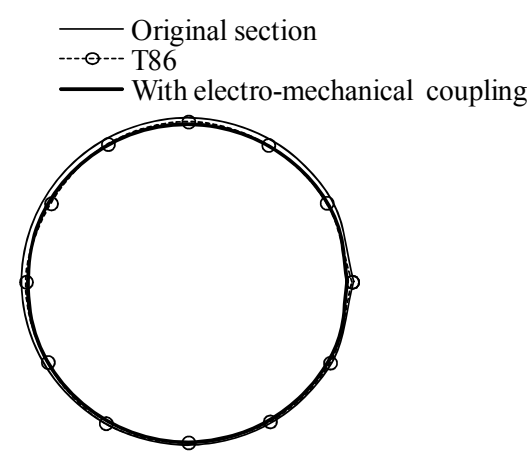

(a) T86

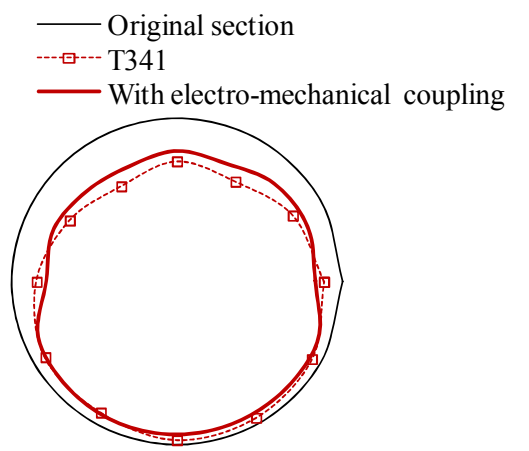

(b) T341

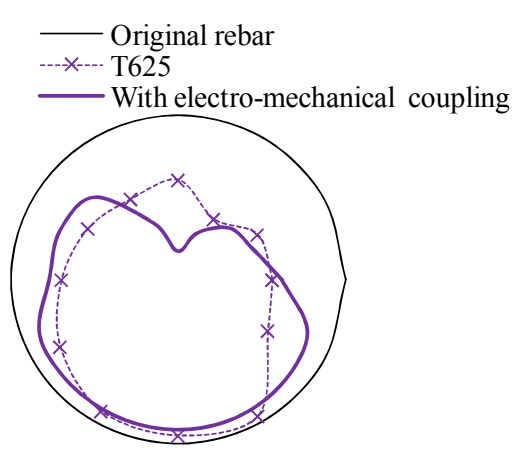

(c) $\mathrm{T} 625$

Fig. 22 Modeled residual cross-sections of rebars considering electro-mechanical coupling. 
pling, the truss networks on the boundaries between concrete elements were activated after cracking to simulate water flow through cracks. For these truss elements, the relative permittivity was set as that of salty water. The analytical results, however, showed no appreciable effect of boundary truss networks on the corrosion process (Fig. 23), although the relative permittivity applied was nearly 15 times that of the internal truss elements. The possible reason is that, within the investigated range of corrosion degree, the cross-section area of boundary truss elements is still small due to a small crack width.

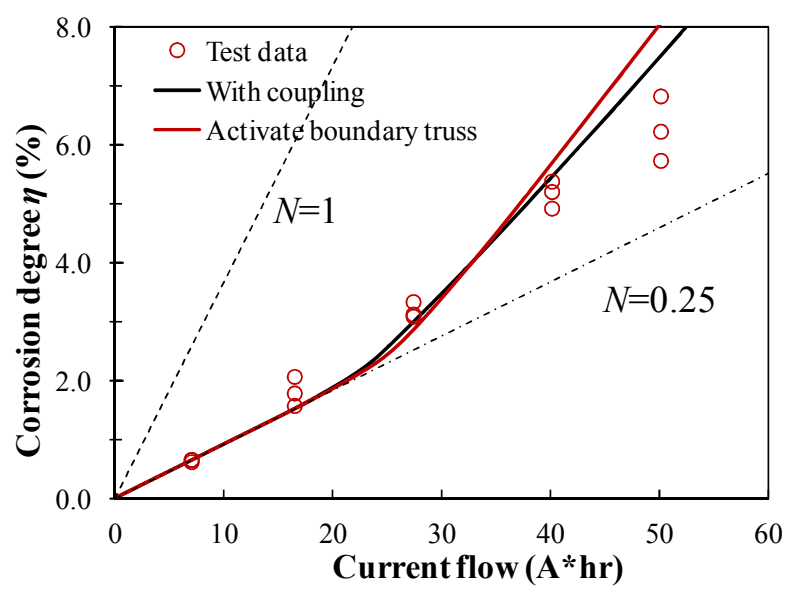

Fig. 23 Modeled corrosion process.

\subsection{Crack pattern}

Figure 24 shows the simulated internal crack patterns considering electro-mechanical coupling. The cracks are plotted in different colors, depending on the crack width. It appears that within a lower corrosion degree than $3.19 \%$ (T341), the crack conditions predicted agree well with the test results (Fig. 7), not only in the pattern but also in the crack width and length. With a further increase of corrosion degree, however, the cracks were observed to propagate faster than those in the test. During the tests of T500 and T625, a few corrosion products exuded from the two sides of the specimens where the rebars extended, which could reduce the expansion pressure and delay the crack development.

\subsection{Tensile behavior of corroded rebars}

With the proposed electro-mechanical model, the radius losses of the rebars due to accelerated corrosion can be reasonably predicted. These radius losses were used to evaluate the residual tensile capacity of the corroded rebars. The load-elongation curves predicted for the cases of T341 and T625 are shown in Fig. 25. It was observed that, when the corrosion degree is increased by approximately $3 \%$, the yield load slightly decreases and the ultimate load reduces by $2.8 \mathrm{kN}$. This is in agreement with the test data. The strains along the rebar obtained in the analysis are compared with those by the image processing method as shown in Fig. 26, in which two load states in the strain hardening stage were considered. It
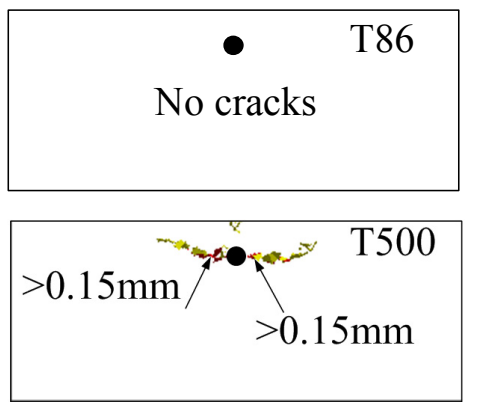
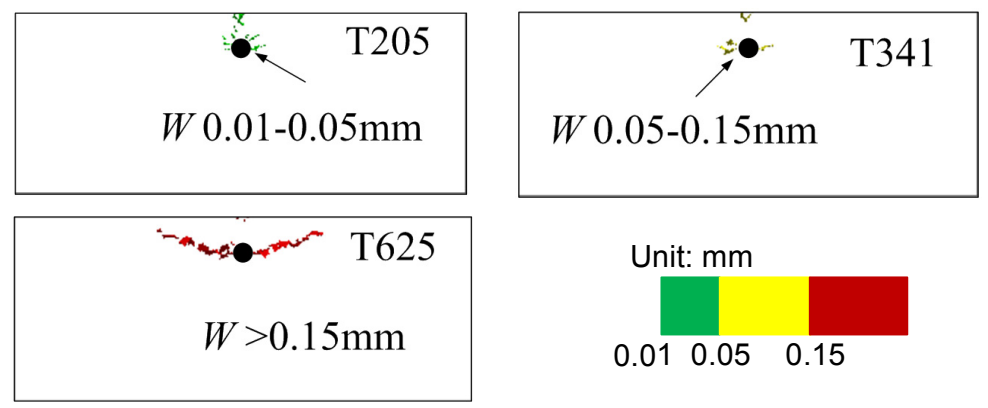

Fig. 24 Modeled internal crack patterns at various corrosion amounts.

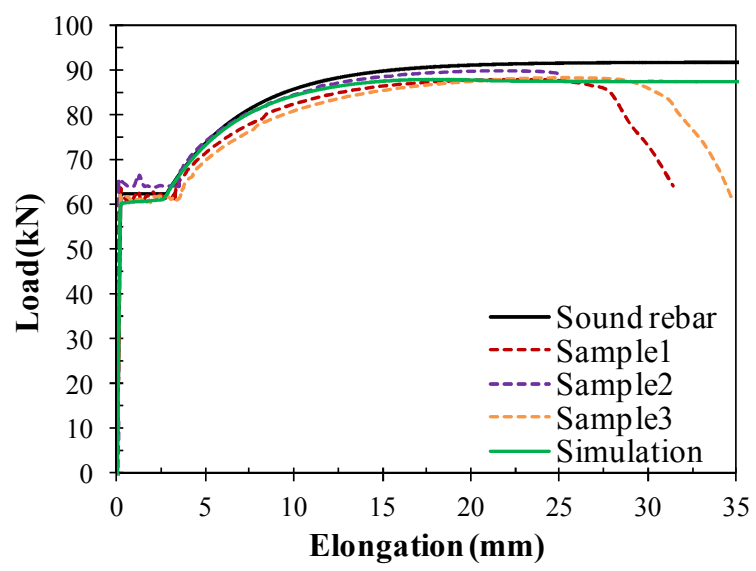

(a) T341

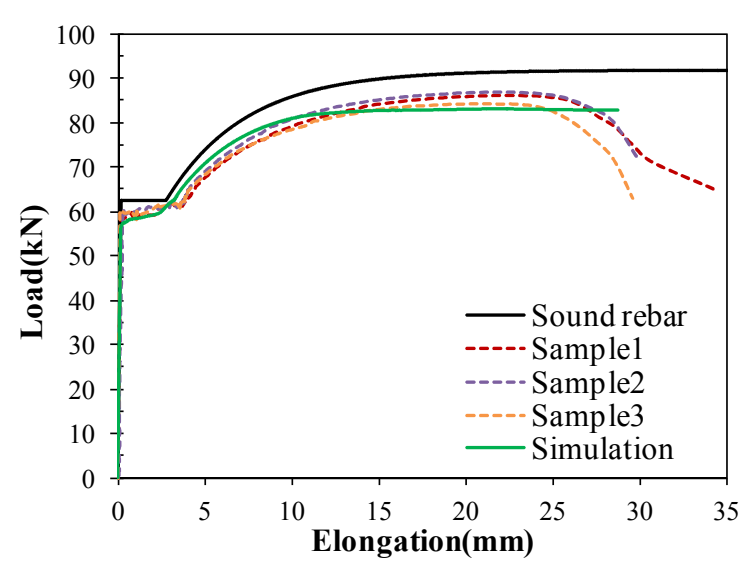

(b) T625

Fig. 25 Modeled load-elongation curves. 
can be seen that the strain distributions along the rebar are also in accordance with the test results.

The generally great conformity with the accelerated corrosion test results in terms of corrosion degree and profile, internal crack pattern, and tensile behavior of corroded rebars confirms that the proposed electromechanical model can quantitatively predict the damage of reinforced concrete when subjected to accelerated corrosion with impressed current.

\section{Application of electro-mechanical model}

The electro-mechanical model described above was used to model the former experiment reported in (Qiao et al. 2015b). This test was performed to study the crack pattern caused by localized corrosion along rebar length. The geometry and test setup of the experiment are shown in Fig. 27. A rebar of $19 \mathrm{~mm}$ in diameter embedded in the concrete of $600 \times 500 \times 200 \mathrm{~mm}^{3}$ was subjected to accelerated corrosion. The concrete used in the experiment was characterized by a compressive strength of $39 \mathrm{MPa}$. A shorter $\mathrm{NaCl}$ pond than the rebar was set on the concrete cover to concentrate the corrosion within the center of the rebar; the current density applied was $900 \mu \mathrm{A} / \mathrm{cm}^{2}$. After the corrosion test, the concrete specimens were cut along the cross-section of the rebar with an interval of $100 \mathrm{~mm}$ to examine the internal crack patterns.

Figure 28 shows the RBSM model used in the analysis. The region marked in yellow on the top surface of the model was assumed to be cathode $(0 \mathrm{~V})$, which cor-

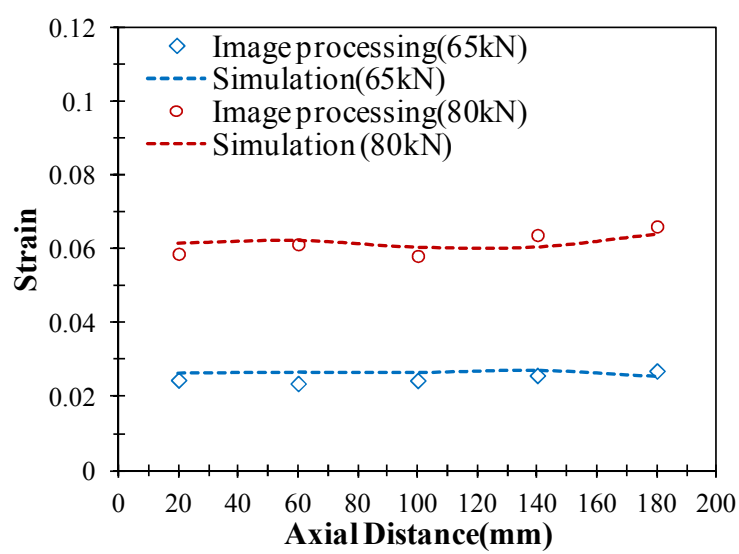

(a) T341 responds to the size and position of the $\mathrm{NaCl}$ pond used in the test. A rebar element was treated as the anode with a fixed potential of $10 \mathrm{~V}$. The corrosion distribution along the rebar and the resulting crack pattern were simulated considering electro-mechanical coupling.

Figure 29 shows the comparison between the predicted corrosion degrees and the experimental results, in which the test data represents the average value of each rebar portion (about 50mm long) after exposed to accelerated corrosion. It was found that the modeled corrosion distribution is similar to the test results at a close current flow of $103.93 \mathrm{~A} * \mathrm{hr}$. Furthermore, the analysis without considering crack effect was carried out for comparison. It can be seen that this analysis clearly underestimated the corrosion degree of the rebar part under $\mathrm{NaCl}$ pond, suggesting that the cracks generated

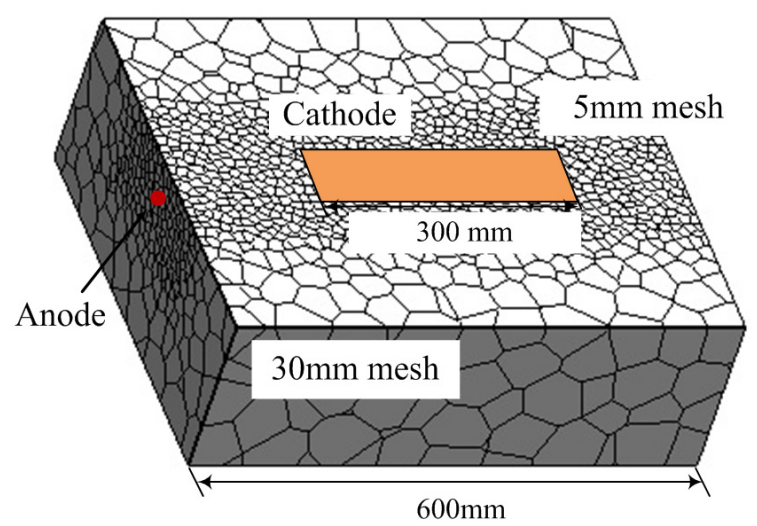

Fig. 28 RBSM model of test specimen.

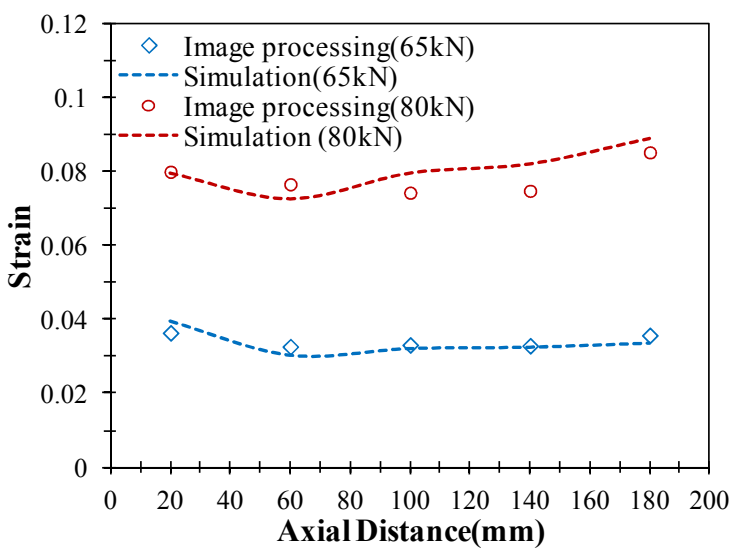

(b) T625

Fig. 26 Modeled strain distributions along the rebar length.
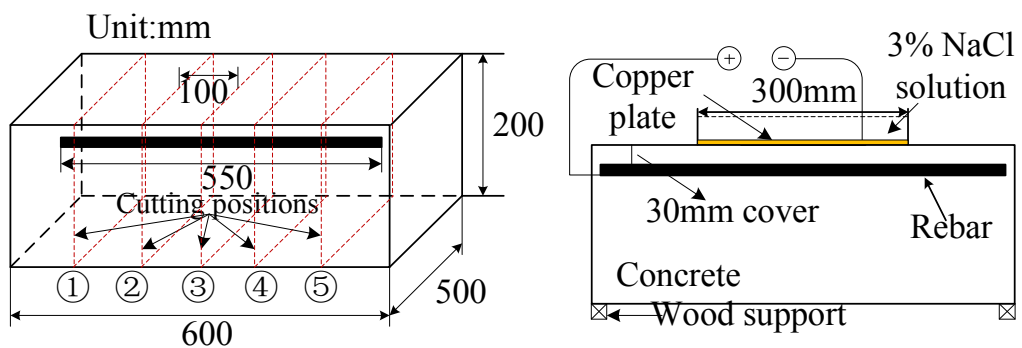

Fig. 27 Geometry and test setup for crack pattern caused by localized corrosion. 
may aggravate the corrosion process in the center part of the specimen.

The modeled surface and internal crack patterns are shown in Fig. 30. The color legend for crack width as described in Fig. 24 was used herein. As can be seen, the simulation demonstrates a similar cracking behavior to the test results. A longitudinal crack with several secondary cracks was observed on the concrete surface. Inside concrete, the crack pattern was found to vary along the rebar length, and inclined lateral cracks were observed in the area under the $\mathrm{NaCl}$ pond, which could cause cover spalling.

\section{Conclusions}

This paper reported the development of an electromechanical model for evaluating the corrosion-caused damage in reinforced concrete. The corrosion test using impressed current through a $\mathrm{NaCl}$ pond on the concrete

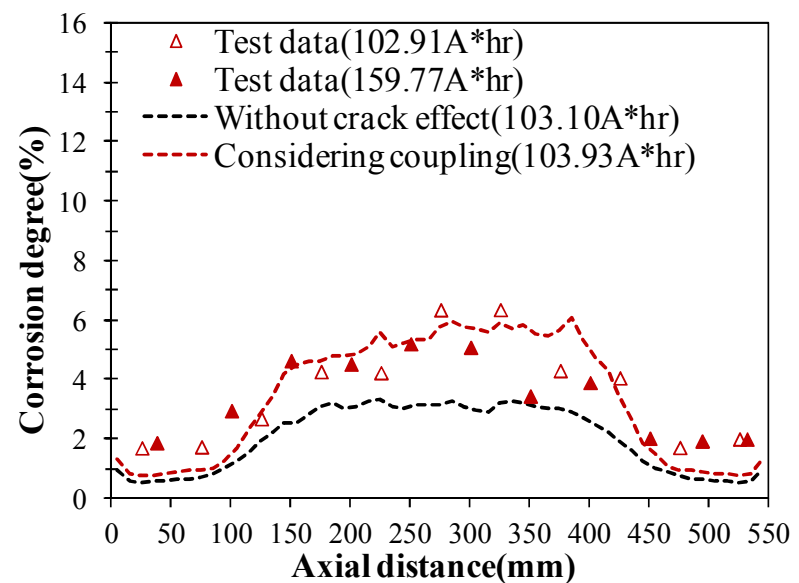

Fig. 29 Modeled corrosion distribution along the rebar length. cover was carried out to validate the applicability of the proposed model. The model was further applied to analyze the crack pattern due to localized corrosion along the rebar length, which was compared with the test results. The following conclusions can be derived from this study:

(1) The test method can produce non-uniform corrosion around the rebar. More corrosion was observed on the rebar surface facing the concrete cover, and the forming cracks can increase the variation of corrosion rates between different rebar parts.

(2) The proposed electro-mechanical model is appropriate to simulate electric corrosion process and corrosion profile, since the model accounts for the interaction between corrosion and concrete cracking by relating the current efficiency to the crack width near the rebar. The analytical results suggest that the forming cracks of $0.1 \mathrm{~mm}$ and more in the concrete could significantly increase the corrosion rate of the rebar part nearby.

(3) The proposed model is able to quantitatively simulate the corrosion-caused damage in terms of concrete crack propagation and degradation of tensile performance of the rebar. The merit of this model is that the local radius losses required for mechanical analysis are automatically calculated using the truss networks model with a simple relationship between current efficiency and crack width, which does not require the assumption on corrosion degree and distribution.

(4) The analysis of crack propagation due to localized corrosion showed that in the section with concentrated corrosion the lateral crack inclines to the concrete surface, which may cause cover spalling. This is in good agreement with the test results.

(5) The proposed electro-mechanical model could be a

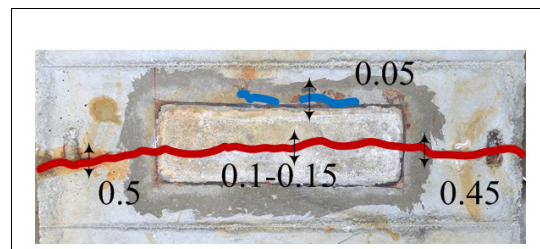

Unit: mm

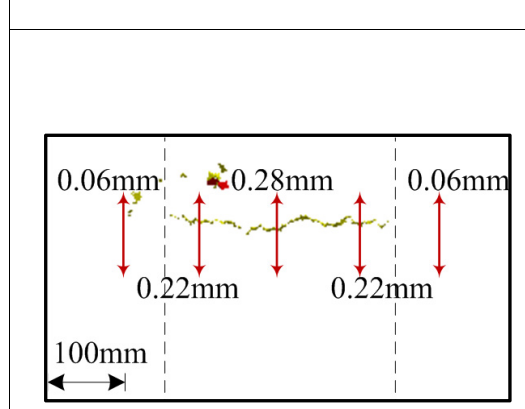

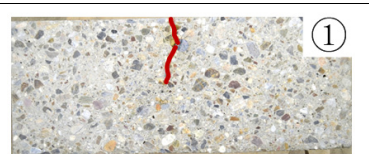

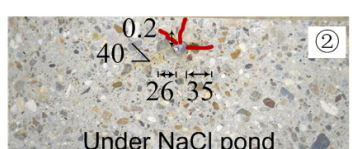

Under $\mathrm{NaCl}$ pond

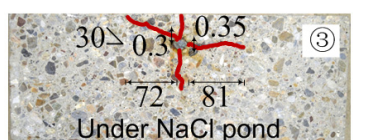

Under $\mathrm{NaCl}$ pond
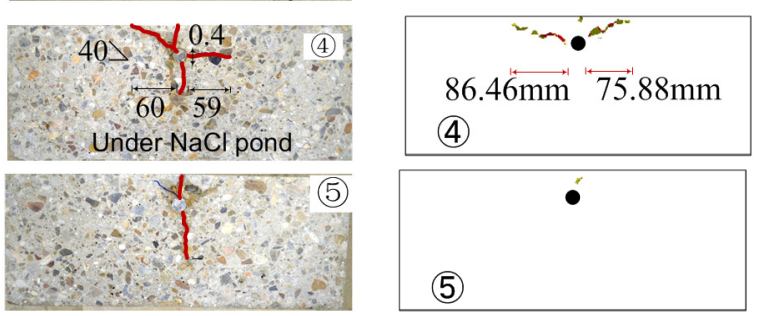

Fig. 30 Comparison of modeled crack patterns with test results. 
good tool for conducting experimental studies of structural response of corroded RC members using the impressed current technique. To fully understand the corrosion-caused damage and predict the durability of RC structures in corrosive environments, modeling of natural corrosion process is desired, which involves more complex mechanisms. In future studies, the electro-mechanical model will be extended to natural corrosion.

\section{Reference}

Andrade, C., (1993). "Calculation of chloride diffusion coefficients in concrete from ionic migration measuements." Cement and Concrete Research, 23(3), 724-742.

Bažant, Z. P., (1979). "Physical model for steel corrosion in concrete sea structures - theory." Journal of the Structural Division, ASCE, 105(ST6), 11371153.

Bolander, J. E. and Saito, S., (1998). "Fracture analysis using spring network models with random geometry." Engineering Fracture Mechanics, 61, 569-591.

Cairns, J., Plizzari, G. A., Du, Y. G., Law, D. W. and Franzoni, C., (2005). "Mechanical properties of corrosion-damaged reinforcement." ACI Material Journal, 102(4), 256-264.

Caré, S. and Raharinaivo, A., (2007). "Influence of impressed current on the initiation of damage in reinforced mortar due to corrosion of embedded steel." Cement and Concrete Research, 37, 1598-1612.

Conyers, L. B., (2013). "Ground-penetration radar for archeology." 3nd ed. Maryland: AltaMira Press. 50.

Coronelli, D. and Gambarova, P., (2004). "Structural assessment of corroded reinforcing concrete beams: modeling guidelines." Journal of Structural Engineerng, ASCE, 130, 1214-1224.

Djerbi, A., Bonnet, S., Khelidj, A. and Baroghel-bouny, V., (2008). "Influence of traversing crack on chloride diffusion into concrete." Cement and Concrete Research, 38, 877-883.

Duffó, G., Gaillard, N., Mariscotti, M. and Ruffolo, M., (2015). "Application of gamma-ray radiography and gravimetric measurements after accelerated corrosion tests of steel embedded in mortar." Cement and Concrete Research, 74, 1-9.

Ishida, T., Iqbal, P. O. N. and Anh, H. T. L., (2009). "Modeling of chloride diffusivity coupled with nonlinear binding capacity in sound and cracked concrete." Cement and Concrete Research, 39(10), 913923.

JIS Z 2241, (2011). "Metallica materials - Tensile testing- Method of test at room temperature ." Tokyo: Japanese Standard Association.

JIS G 3122, (2010). "Steel bars for concrete reinforcement." Tokyo: Japanese Standard Association.

Kato, B., (1979). "Mechanical properties of steel under load cycles idealizing seismic action." CEB Bulletin D'Information, 131, 7-27.
Lundgren, K., (2002). "Modeling the effect of corrosion on bond in reinforced concrete." Magazine of Concrete Research, 54(3), 165-173.

Mada, T., (2011). "Automatic Fourier analysis by EXCEL." Technical Report of Technology Service Division, Research Institute of Applied Mechanics, Kyushu University, 12, 1-8. (in Japanese)

Malumbela, G., Moyo, P. and Alexander, M., (2009). "Behavior of RC beams corroded under sustained service loads." Construction and Building Materials, 23, 3346-3351.

Malumbela, G., Moyo, P. and Alexander, M., (2012). “A step towards standardizing accelerated corrosion tests on laboratory reinforced concrete specimen." Journal of South African Institute of Civil Engineering, 54(2), 78-85.

Mangat, P. S. and Elgarf, M. S., (1999). "Flexural strength of concrete beams with corroding reinforcement." ACI Structural Journal, 96(1), 149-158.

Moliton, A., (2007). "Basic electromagnetism and materials." New York: Springer. 51-56.

Morinaga, S., (1996). "Remaining life of reinforced concrete structures after corrosion cracking." Durability of Building Materials and Components, In: C. Sjostrom, ed., E\&FN Spon, London, 127-137.

Nakamura, H., Srisoros, W., Yashiro, R. and Kunieda, M., (2006). "Time-dependent structural analysis considering mass transfer to evaluate deterioration process of RC structures." Journal of Advanced Concrete Technology, 4(1), 147-158.

Nossoni, G. and Harichandran, R., (2012). "Current efficiency in accelerated corrosion testing of concrete." Corrosion, 68(9), 801-809.

Ožbolt, J., Oršanić, F., Balabanić, G. and Kušter, M., (2012). " Modeling damage in concrete caused by corrosion of reinforcement: coupled 3D FE model." International Journal of Fracture, 178, 233-244.

Poursaee, A. and Hansson, C. M., (2009). "Potential pitfalls in assessing chloride-induced corrosion of steel in concrete." Cement and Concrete Research, 39, 391-400.

Qiao, D., Nakamura, H., Yamamoto, Y. and Miura, T., (2015a). "Evaluation method of tensile behavior of corroded reinforcing bars considering radius loss." Journal of Advanced Concrete Technology, 13, 135146.

Qiao, D., Nakamura, H., Tran, K. K., Yamamoto, Y. and Miura, T., (2015b). "Experimental and analytical evaluation of concrete cover spalling behavior due to local corrosion." Journal of Structural Engineering, JSCE, 61A, 707-714.

Tran, K. K., Nakamura, H., Kawamura, K. and Kunieda, M., (2011). "Analysis of crack propagation due to rebar corrosion using RBSM." Cement and Concrete Composite, 33(9), 906-917.

Yamamoto, Y., Nakamura, H., Kuroda, I. and Furuya, N., (2008). "Analysis of compression failure of concrete by three-dimensional rigid body spring model." 
Journal of Materials, Concrete Structures and Pavement, 64(4), 612-630. (in Japanese)

Yamamoto, Y., Nakamura, H., Kuroda, I. and Furuya, N., (2014). "Crack propagation analysis of reinforced concrete wall under cyclic loading using RBSM." European Journal of Environmental and Civil Engineering, 18(7-8), 780-792.
Yuan, Y., Ji, Y. and Shah, S. P., (2007). "Comparison of two accelerated corrosion techniques for concrete structures." ACI Material Journal, 104(3), 344-347.

Zhang, W. P., Song, X. B., Gu, X. L. and Li, S. B., (2012). "Tensile and fatigue behavior of corroded rebars." Construction and Building Materials, 34, 409-417. 